Revista Voluntas: Estudos sobre Schopenhauer - Vol. 3, Números 1 e 2 - $1^{\circ}$ e $2^{\circ}$ semestres de 2012 - ISSN: 2179-3786 - pp. $203-210$.

\title{
Schopenhauer e os vínculos entre vontade, intuição e racionalidade
}

\author{
Schopenhauer and the ties between will, intuition and rationality
}

\author{
Eduardo Ribeiro da Fonseca \\ Psicanalista e Doutor em Filosofia Moderna e Contemporânea pela USP. \\ Professor de Psicologia da Violência na Escola Superior de Polícia Civil do Paraná. \\ E-mail: eduardorfonseca@uol.com.br
}

\begin{abstract}
Resumo: O organismo (Organismus) humano é, na visão de Schopenhauer, manifestação da Vontade e o corpo (Leib) Vontade objetivada. Neste sentido, existe uma relação dependente do intelecto em relação à Vontade. Esta aparece frente ao psiquismo como a manifestação de um querer inconsciente, e, a partir disso, define-se o intelecto como coisa física e consciente, em contraste com a Vontade, que é metafísica e inconsciente. A racionalidade é um aspecto do psiquismo humano e não seu fundamento. Mais fundamental é a intuição intelectual proporcionada pelo entendimento, que realmente capta e dá forma ao mundo, através das formas básicas a priori do tempo, do espaço, e da causalidade. Ao fundo das intuições intelectuais e das abstrações conceituais, no entanto, estão aspectos afetivos, que efetivamente direcionam o intelecto e determinam o posicionamento psíquico frente à efetividade.
\end{abstract}

Palavras-chave: Vontade; Intelecto; Inconsciente.

Abstract: The human organism (Organismus) is, according to Schopenhauer, a manifestation of the Will and the body (Leib) Will objectified. Thus, there is a relationship dependent on the intellect in relation to Will. This appears opposite the psyche as the manifestation of an unconscious wish, and from that, the intellect is defined as a physical thing and conscious, in contrast to Will, which is metaphysical and unconscious. Rationality is an aspect of the human psyche and not its foundation. More fundamental is the understanding afforded by intellectual intuition, that really captures and shapes the world through basic a priori forms of time, space, and causality. In the background of intellectual intuitions and conceptual abstractions, however, are affective aspects, which effectively direct the intellect and determine placement psychic front of effectiveness.

Keywords: Will; Intellect; Unconscious.

„Die Wahrheit kann warten: denn sie hat ein lange Leben vor sich“

(Schopenhauer)

A pergunta sobre o papel do intelecto e de suas imperfeições na Metafísica da Vontade nos leva a pensar a visão de Schopenhauer acerca da fisiologia e da psicologia humanas. Nesse sentido, o filósofo busca a compreensão da subjetividade, a partir do impulso cego e inconsciente que subjaz às atividades psíquicas e que, secretamente, as determinam, tal como ocorre na relação entre o boneco e seu manipulador em um teatro de marionetes.

Para o filósofo da Vontade, a racionalidade é um aspecto secundário do psiquismo humano e não seu fundamento. Mais fundamental é a intuição intelectual proporcionada pelo entendimento, que realmente capta e dá forma ao mundo, através das formas básicas a priori do tempo, do espaço, e da 
causalidade. Ao fundo das intuições intelectuais e das abstrações conceituais, no entanto, estão aspectos afetivos, que efetivamente direcionam o intelecto e determinam o posicionamento psíquico frente à efetividade. Eles são o próprio fundamento da ordem psíquica, mas, no entanto, eles mesmos não têm fundamento, o que nos coloca frente ao conflito psíquico entre a potência inconsciente do organismo, que é a própria visibilidade da Vontade, e o seu instrumento, o intelecto, que só pode fornecer uma leitura da ordem exterior do mundo, mas que não determinam o querer. Isto nos remete à seguinte pergunta: Como Schopenhauer analisa as relações entre vontade e intelecto no âmbito de nosso psiquismo, na medida em que se trata, segundo ele, de uma relação entre forças de magnitude muito desproporcional?

Para o filósofo, o intelecto está sujeito a inúmeras vicissitudes e imperfeições, como os lapsos e a perda da memória, o envelhecimento e a decrepitude. Por outro lado, segundo ele, não ocorre uma degradação correspondente da vontade. Pelo contrário, a vontade é sempre de natureza idêntica, e mostra-se no apego à vida, nos cuidados individuais e pela perpetuação da espécie humana com todas as suas implicações sexuais, assim como também no egoísmo e na falta de consideração para com os outros, juntamente com as emoções que surgem dessas e outras manifestações do querer-viver. Portanto, todas essas manifestações diferentes e algumas delas contraditórias, levam o filósofo à constatação de que a Vontade crava os dentes em sua própria carne no âmbito da efetividade.

Schopenhauer sugere que "mesmo no menor inseto" está presente a vontade "completa e total", que quer o que ela quer tão decidida e completamente quanto o homem. A diferença está apenas no objeto do querer, ou seja, nos motivos, mas isto, segundo o filósofo, é coisa do intelecto.

$\mathrm{Na}$ nomenclatura de Schopenhauer, a diferença entre o desejo e o querer está no caráter hipotético do primeiro, enquanto que, no caso do segundo, há uma correspondência direta com o caráter originário do organismo. O desejo está no âmbito da conjunção entre o intelecto e a vontade, e pode ser conhecido a priori, enquanto o querer é a pura característica daquela vontade expressa no organismo que quer tal como é, e é tal como quer - por isso, só pode ser reconhecido a posteriori, pelo ato e pela série sucessiva de atos que ao final modelam um mapa de suas características, do qual tomamos os traços principais e exemplos, mas que, ainda assim, não será necessariamente exaustivo. O grau de compreensão desse caráter inato ao organismo dependerá do quanto pudermos reconhecer acerca de sua efetiva orientação empírica, isto é, dos atos daquela vontade.

Uma das coisas que determinam a dificuldade de entendimento acerca do querer está nas características do intelecto. Por ser secundário e vinculado ao organismo, ele apresenta inúmeros graus de perfeição, e, em geral, é essencialmente limitado e imperfeito. A vontade, por outro lado, como

\footnotetext{
${ }^{1}$ SCHOPENHAUER, A. Sämtliche Werke, Band II, Die Wille als Wille und Vorstellung, II. Stuttgart/ Frankfurt am Main: Cotta-Insel, cap. 19, p. 266.
} 
aquilo que é originário e a coisa em si, nunca pode ser imperfeita, mas todo ato de vontade é totalmente o que pode ser.

Assim, as figuras do apetite (Begierde) e do desejo (Wunsch) sempre surgem para a consciência como disposições e determinam limites à percepção, ao imporem a sua lei com constância perturbadora, o que significa que eles interferem objetivamente no processo intelectual, tais como a interferência no processo de recordação; a memória seletiva e a ausência de contato com recordações dolorosas; a ativação e o aumento momentâneo da própria capacidade intelectual para obter os objetos interessantes à vontade, entre outros.

No texto sobre a objetivação da Vontade no organismo animal, o filósofo escreve:

Toda paixão, de fato toda inclinação ou aversão, tinge os objetos do conhecimento com a sua cor. O que ocorre com mais facilidade é o falseamento do conhecimento pelo desejo e pela esperança, que nos fazem ver o que é meramente possível em cores deslumbrantes, como se fosse algo provável e quase certo, e nos torna quase incapazes de compreender o que se opõe a isto ${ }^{2}$.

Isso mostra a preponderância da vontade sobre o intelecto, talvez até mesmo por sua simplicidade, baseada apenas na báscula entre o interesse e a aversão, pois a sua natureza essencial exige que ela seja sempre inteiramente ela mesma - e essa sua natureza essencial na efetividade se resume ao querer e ao não querer alguma coisa.

Sua função consiste em querer e em não querer, o que opera com a maior facilidade e sem esforço, e, como diria um camelô, não requer prática nem habilidade. Não é preciso ensinar ninguém a querer.

Por outro lado, conhecer tem muitas funções diferentes entre si, e não ocorre inteiramente sem esforço, pois necessita fixar a atenção para tornar o objeto claro, e em um grau mais elevado, também para pensar e deliberar, pelo que esta função é capaz de obter grande aperfeiçoamento através da prática e do treinamento.

Se o intelecto apresenta à vontade algo simples e perceptível, a vontade de uma só vez expressa a sua aprovação ou desaprovação. Este é o caso, mesmo quando o intelecto laboriosamente ponderou e ruminou, para finalmente produzir a partir de inúmeros dados e por meio de combinações difíceis, o resultado que parece mais de acordo com os interesses da vontade. No capítulo XIX do Tomo II de $O$ Mundo como Vontade e Representação, o filósofo traz uma divertida imagem dessa relação entre a vontade e os esforços do intelecto, que como um grão-vizir tenta convencer o querer com argumentos racionais. Enquanto isso, a vontade como um sultão fica à toa repousando; após o resultado do extenso

\footnotetext{
${ }^{2}$ SCHOPENHAUER, A. Sämtliche Werke, Band II, Die Wille als Wille und Vorstellung, II. Stuttgart/ Frankfurt am Main: Cotta-Insel, cap. 15, p. 182.
} 
labor intelectual ser alcançado, ela se manifesta. Escreve Schopenhauer: "Ela entra em cena apenas para expressar mais uma vez a sua monótona aprovação ou desaprovação, como o sultão faz no divã. É verdade que isso pode ocorrer em graus variados, mas em essência permanece sempre a mesma coisa"3.

Para Schopenhauer, essas naturezas fundamentalmente diferentes de vontade e intelecto, a simplicidade e originalidade essencial da primeira, em contraste com o caráter complicado e secundário do segundo, pode se tornar ainda mais clara para nós se observarmos a sua "estranha interação dentro de nós”. Assim, vemos em um determinado caso como as imagens e pensamentos que surgem no intelecto definem as comoções da vontade, e como são inteiramente separados e diferentes os papéis de ambos.

No caso das fantasias e devaneios essa relação se explicita de um modo interessante, pela forma como simples imagens atuam sobre a vontade.

Schopenhauer diz que se nós, por exemplo, estamos sozinhos, e pensamos sobre nossos assuntos pessoais, e depois concebemos vividamente, por exemplo, a ameaça de um perigo realmente presente, e a possibilidade de um resultado infeliz, a ansiedade de uma só vez comprime o coração, e o sangue deixa de fluir. Schopenhauer:

Mas, se o intelecto conceba a possibilidade de um resultado oposto, e permite que a imaginação conceba a felicidade tão longamente esperada como sendo alguma coisa que possa ser finalmente atingida, então nossa pulsação se acelera de uma só vez com alegria, e o coração se sente leve como uma pena, até que o intelecto acorde de seu sonho. Caso recordemos alguma situação antiga na qual sofremos um insulto ou ofensa, então a raiva e o ressentimento agitam o nosso peito que no momento anterior estava em paz. Do mesmo modo, deixe a imagem de um velho amor perdido surgir, evocada por acidente, com a qual esteja ligado um romance inteiro com suas cenas de magia, e esta raiva vai uma vez mais dar lugar à saudade profunda e à tristeza. Finalmente, se nos ocorre algum incidente humilhante de épocas passadas, nós murchamos; gostaríamos de ser engolidos pela Terra, coramos de vergonha, e muitas vezes tentamos desviar nossa atenção desse pensamento e distrair-nos à força dele por meio de algum impropério, como se estivéssemos afugentando maus espíritos. ${ }^{4}$

Ou seja, como a vontade é em si mesma inconsciente, mero ímpeto cego, vemos que quando o intelecto toca sua música ela deve dançar para ele, como diz o filósofo:

$\mathrm{Na}$ verdade, ela faz o papel de uma criança a quem sua babá prazerosamente entretém narrando histórias que se alternam entre coisas alegres e tristes. Isto ocorre porque a

\footnotetext{
${ }^{3}$ SCHOPENHAUER, A. Sämtliche Werke, Band II, Die Wille als Wille und Vorstellung, II. Stuttgart/ Frankfurt am Main: Cotta-Insel , cap. 19, p. 267.

${ }^{4}$ SCHOPENHAUER, A. Sämtliche Werke, Band II, Die Wille als Wille und Vorstellung, II. Stuttgart/ Frankfurt am Main: Cotta-Insel , cap. 19, p. 268.
} 
vontade é, em si mesma, sem conhecimento, mas, o entendimento [Verstand] que lhe acompanha não possui vontade própria."

Do mesmo modo que a vontade só pode se orientar pela consciência, existe também a representação do mundo externo com a necessidade causal que é inerente ao intelecto humano. No entanto, como em Freud, essa relação do desejo com a efetividade preserva sempre um resíduo de mal-estar.

Uma das interessantes manifestações disso está no capítulo sobre o humor que consta do Tomo II. Em geral, o riso é um estado prazeroso. A percepção da incongruência entre o pensamento e a intuição, isto é, a efetividade, deixa-nos alegres e nos entregamos com muito gosto ao abalo convulsivo [krampfhaten Erschütterung] que essa percepção provoca.

Segundo Schopenhauer, o fundamento disso é a seguinte:

Em cada um dos súbitos contrastes que aparecem entre o intuído e o concebido, o que é intuído está sempre indubitavelmente certo, porque a intuição não está sujeita ao erro e nem necessita de confirmação vinda de fora, pois ela é advogada de si mesma. Seu conflito com o pensamento resulta do fato de que este último, com seus conceitos abstratos, não pode abarcar a infinita variedade de matizes e as delicadas sutilezas do que é intuído. Esta vitória do conhecimento intuitivo sobre o pensamento nos alegra. Isto ocorre porque a intuição é originária ${ }^{5}$.

Portanto, o vínculo profundo da vontade com a intuição, reside na observação de que a última é o médium do presente, do prazer e da alegria. Ela não depende de nenhum esforço.

Porém, com o pensamento ocorre o contrário, pois ele é o conhecimento em segunda potência, cujo exercício requer algum esforço, que às vezes é até elevado. Aliás, para o filósofo, o pensamento é a forma de conhecimento na qual na qual os conceitos contrariam a satisfação [Befriedigung] de nossos desejos imediatos [unmittelbaren Wünsche], pois como intermediária entre passado, presente $\mathrm{e}$ futuro, e do que é sério, ela age como veículo para os nossos medos, nossos arrependimentos, e nossos cuidados, que são comoções desagradáveis da vontade e que, portanto, repugnam. Por conseguinte, deve ser agradável para nós ver aquela estrita, incansável e também tão problemática governanta, a nossa faculdade de razão [Vernunft], por vezes ser condenada no tribunal da vida por inadequação. É por isso que a expressão do riso e a alegria estão intimamente relacionadas ao fracasso da racionalidade.

A vontade, portanto, sofre na individuação e depende do intelecto para apreciar os objetos disponíveis de satisfação e evitar os objetos de aversão. Contudo, ela demonstra novamente a sua

\footnotetext{
${ }^{5}$ SCHOPENHAUER, A. Sämtliche Werke, Band II, Die Wille als Wille und Vorstellung, II. Stuttgart/ Frankfurt am Main: Cotta-Insel , cap. 8, p. 130.
} 
primazia quando, mesmo fazendo o jogo do intelecto, e permitindo que este a controle em certas circunstâncias, ela prontamente retoma a sua supremacia e faz sentir a sua autoridade. Ela faz isso proibindo o intelecto de ter acesso a certas representações, para impedir que determinadas linhas de pensamento [Gedankenreihen] surjam. ${ }^{6}$ Para o filósofo há um saber da vontade que ela experimenta através do próprio intelecto, de que semelhantes pensamentos despertariam qualquer uma das comoções [Bewegungen] desagradáveis anteriormente sugeridas.

Ela então segura as rédeas entre os dentes e controla o intelecto, forçando-o a se direcionar [richten] para outras coisas. No entanto, ainda que muitas vezes isso seja difícil, o sucesso é certo a partir do momento em que a vontade leve isso a sério; pois, a resistência [Widerstreben] não provém do intelecto, que sempre permanece indiferente, mas parte da própria vontade. Da resistência e do redirecionamento do intelecto surge o recalque da representação e a afirmação da vontade, mesmo onde isso parece contraditório do ponto de vista do pensamento consciente. E, mesmo quando o intelecto parece tomar decisões, não é bem assim.

A vontade autodiscordante pode ter uma inclinação em um sentido por uma representação, que, por outro lado, seja também abominada. Nesse caso, a representação é em si mesma interessante à vontade, pois a excita. Ao mesmo tempo, entretanto, o conhecimento abstrato diz à vontade que essa representação vai causar um choque de emoção dolorosa que é indigna e sem qualquer propósito, como o filósofo escreve no capírtulo XIX dos Complementos. A vontade então decide de acordo com esse último conhecimento, e força o intelecto a obedecer. Ou seja, não é o intelecto que quer o que é racional, mas o racional se mostra, em certo momento, interessante à vontade. O que não quer dizer que o apetite (Begierde) muito intenso da vontade ou um desejo (Wunsch) especialmente decisivo por alguma coisa, não possam preponderar sobre o que é considerado racional pelo intelecto naquele momento. Em tal situação, o intelecto testemunha a necessidade de uma ação completamente contrária à sua tendência analítica e nada pode fazer para modificar a orientação da ação efetiva.

Essa relação dependente do intelecto com a vontade é tal como escreve Freud no segundo capítulo de $O E$ U (Ich) e o Isso (ES) a respeito das relações dependentes entre as duas instâncias.

Em Freud, o Isso é a sede das pulsões, enquanto o Eu rege os acessos à motilidade, na medida em que está em contato direto com o mundo externo. Por isso, Freud, como Schopenhauer, compara o $\mathrm{Eu}$ ao cavaleiro, que rege e controla as forças do cavalo, que são superiores às suas. Por esta razão, o cavaleiro muitas vezes se vê obrigado a se deixar conduzir pelo cavalo, ou seja, transformar em ação a vontade do Isso. ${ }^{7} \mathrm{Na}$ verdade, o cavaleiro conduz quando as coisas que são relativamente indiferentes ou proporcionais, mas quando o desejo se mostra intenso, a relação se mostra como é. O eu consciente

\footnotetext{
${ }^{6}$ Naturalmente, como salta aos olhos do leitor sem preconceitos, trata-se do tema psicanalítico da associação de ideias e da livre-associação, cuja contraparte é a escuta flutuante do psicanalista, tratado magistralmente por Freud no seu texto intitulado "Zur Einleitung der Behand Lung" [Sobre o início do tratamento], publicado originalmente em 1913.
} 
freudiano dessa época pode ser comparado ao conceito de intelecto de Schopenhauer, que está para o Isso, como o intelecto está para a vontade.

$\mathrm{Na}$ concepção do filósofo de Frankfurt, o senhor [Herr] é a vontade, o servo [Diener] o intelecto. Em última instância, a vontade está sempre no comando e, portanto, constitui o núcleo real, o ser em si do homem. Desse modo, a preponderância da vontade imprime sobre o intelecto o selo da subjetividade, do perspectivismo, da unilateralidade.

$\mathrm{Na}$ verdade, porém, a alegoria [Gleichniß] mais satisfatória para expressar a relação entre os dois é a do homem forte e cego, que representa o querer, e carrega sobre os seus ombros um paralítico que é capaz de ver, o intelecto. Sem dúvida é uma belíssima imagem.

A relação entre vontade e intelecto aqui descrita pode ser ainda melhor reconhecida no fato de que o intelecto é originariamente bastante estranho às decisões da vontade. Aquele fornece a esta os motivos [Motive]. Mas, apenas subsequentemente e, portanto, totalmente a posteriori, ele aprende como eles atuaram, assim como um homem que faz um experimento químico aplica os reagentes, e aguarda o resultado.

$\mathrm{Na}$ verdade, o intelecto permanece bastante excluído das reais resoluções e das decisões secretas de sua própria vontade, que às vezes só pode conhecer como o faria um estranho, espionando e tomando de assalto: ele deve surpreender a vontade no ato de sua expressão, e assim descobrir suas reais intenções.

Este assalto à casamata da vontade pode ser comparado à perspectiva da psicanálise e dela encontramos inúmeros exemplos na prática clínica. A vontade, portanto, pode ser surpreendida em seus atos, mostrando-se como é e como quer nas coisas mais corriqueiras.

Todas essas relações de mão dupla entre vontade e intelecto, que implicam numa certa proporção, numa possivel predominância momentânea de um ou de outro, mas que pode resultar também num acordo sublimatório ou numa coincidência de interesses têm sempre como pano de fundo a onipotência do querer, a coisa primária, sobre o intelecto cheio de imperfeições.

A natureza o produziu para servir a uma vontade individual. Portanto, ele está destinado a conhecer as coisas apenas enquanto elas possam servir de motivos para essa vontade, e não para sondá-las e compreender a sua verdadeira essência íntima. Para encerrar, eu gostaria de citar o filósofo mais uma vez, em outro trecho do importante capítulo XIX do Tomo II de O mundo como vontade e representação:

O intelecto humano é unicamente uma potencialização do intelecto animal, e assim como o intelecto animal é inteiramente limitado ao presente, também o nosso intelecto

\footnotetext{
${ }^{7}$ FREUD, S. Das Ich und das Es. In: Studienausgabe, Bd. 5, p. 294. A mesma metáfora originada em Schopenhauer está presente também na $31^{\mathrm{a}}$ Vorlesung das Neuen Folge (1933a), Studienausgabe, Bd. 1, p. 514.
} 
mantém fortes traços dessa limitação. Portanto, a memória e a lembrança são muito imperfeitas. (...) A inconciência é o estado originário e natural de todas as coisas, sendo, portanto, também a base a partir da qual, em determinadas espécies de seres, a consciência aparece apenas como a sua mais elevada florescência. E, por esta razão, aquela sempre prevalece. De acordo com isto, muitos seres são sem consciência [ohne Bewußtsein], ainda que eles ajam de acordo com as leis de sua própria natureza, em outras palavras, da sua vontade ${ }^{8}$.

Portanto, Em Schopenhauer, a atividade não é inerente ao intelecto. Ele é dependente e secundário em relação à vontade, conforme o filósofo não se cansa de repetir no Tomo II de $O$ mundo como vontade e representação. O intelecto pode ser pouco exigido, quando submetido a impulsos (Triebe) menos frequentes ou intensos, mas pode, num sentido oposto, vir a ser muito desgastado, e até mesmo estragado, quando submetido a continuados esforços que superam a sua capacidade natural.

No entanto, a vontade em si mesma segue imperturbável no torvelinho da efetividade com todas as suas formas e oportunidades de objetivação do querer, ainda que de modo completamente inconsciente, pois, ao fundo do mundo animal e da consciência humana, resta ainda o mundo orgânico, no qual a vontade age sem a necessidade do apoio do sistema nervoso central, isto é, do cérebro. Assim, da inconsciência ela surge e para a inconsciência ela sempre retornará (de um modo ou de outro: seja na degeneração do intelecto ou na própria morte do organismo), sem perder jamais a impetuosidade cega e originária que a caracterizam.

\section{Referências}

SCHOPENHAUER, A. Sämtliche Werke, Band II, Die Wille als Wille und Vorstellung, II. Stuttgart/ Frankfurt am Main: Cotta-Insel , 1960.

FREUD, S. Das Ich und das Es. In: Die S. Freud-Studienausgabe, Bd. 5. S. Fischer Verlag, 1980. Org. 11 vols., Munique, DTV/ de Gruyter, 2a ed., 1999.

\footnotetext{
${ }^{8}$ SCHOPENHAUER, A. Sämtliche Werke, Band II, Die Wille als Wille und Vorstellung, II. Stuttgart/ Frankfurt am Main: Cotta-Insel, cap. 15, p. 183.
} 